3. Raz I, Okon E, Cheajek-Shaul E. Pulmonary manifestation of Behçet's disease. Chest. 1989;95:585-9.

4. Bang DS, Lee JH, Lee ES, et al. Epidermiologic and clinical survey of Behçet's disease in Korea: the first multicenter study. J Korean Med Sci. 2001;16:L615-8.

5. Erkan F. Pulmonary involvement in Behçet's disease. Curr Opin Pulm Med. 1999;5:314-8.

6. Okita Y, Ando M, Minatoya K, et al. Pseudoaneurysm of aortic arch, right subclavian artery and abdominal aorta in a patient with Behçet's disease. J Vasc Surg. 1998;28:723-6.

7. Nonaka K, Makuuchi H, Naruse J, et al. Pseudoaneurysm of aortic arch and rupture into pericardium, a case report of successful surgical management. Jpn J Thorac Cardiovasc Surg. 1998;46:772-6.

8. Tunaci A, Berkmen YM, Gokmen E. Thoracic involvement in Behçet's disease: pathologic, clinical, and imaging features. Am J Roentgenol. 1995;164:51-6.

\title{
Methylene blue for lithium-induced refractory hypotension in off-pump coronary artery bypass graft: Report of two cases
}

\author{
Donatella Sparicio, MD, Giovanni Landoni, MD, Federico Pappalardo, MD, Martina Crivellari, MD, Elisa Cerchierini, MD,
} Giovanni Marino, MD, and Alberto Zangrillo, MD, Milano, Italy

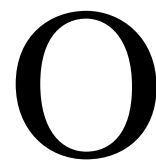
ff-pump surgery is gaining popularity for coronary artery bypass grafting (CABG). We report the perioperative management of 2 patients who self-assumed lithium and had refractory hypotension during beating heart surgery. Both patients had a dramatic hemodynamic improvement after receiving methylene blue.

\section{Clinical Summary}

Two men (57 and 68 years, each weighing $72 \mathrm{~kg}$, height 180 and $186 \mathrm{~cm}$ ) with coronary artery disease and ejection fraction greater than $50 \%$ were scheduled for elective off-pump CABG. Medical history included depression on treatment with benzodiazepines and lithium carbonate (300 mg every 8 hours). They were both on treatment with beta-blockers (atenolol and carvedilol), calcium antagonist (amlodipine), nitrates, and aspirin; patient A also used an angiotensin-converting enzyme inhibitor. Both patients had an unnoticed self-administration of lithium the morning before surgery.

Standard premedication and anesthesia were administered. Target coronary vessels were mechanically stabilized and posterior vessel presentation obtained with a suspension stitch placed in the middle of the 4 pulmonary veins. Both patients received an in situ internal thoracic artery graft to the left anterior descending artery and a saphenous vein graft to the posterior descending and obtuse marginal arteries. Hypotension ensued after pericardial opening and anastomosis. Arterial blood pressure, 80/50 mm Hg (mean

From the Department of Cardiovascular Anesthesia, Vita-Salute University of Milan, IRCCS San Raffaele Hospital, Milan, Italy.

Received for publication June 16, 2003; accepted for publication Sept 12, 2003.

Address for reprints: Donatella Sparicio, MD, Via Olgettina 60, 20132 Milano, Italy (E-mail: Sparicio.donatella@hsr.it).

J Thorac Cardiovasc Surg 2004;127:592-3

$0022-5223 / \$ 30.00$

Copyright @ 2004 by The American Association for Thoracic Surgery

doi:10.1016/j.jtcvs.2003.09.019 arterial pressure $=60 \mathrm{~mm} \mathrm{Hg}$ ), was not responsive to etilephrine boluses, atrial pacing, dopamine infusion $(10 \mu \mathrm{g} / \mathrm{kg} / \mathrm{min})$, steep Trendelenburg position, fluid loading, and opening of both pleura; nevertheless, patients' stability, in the absence of arrhythmias or ST-T changes, maintenance of diuresis, and an optimal cooperation between anesthesiologist and surgeon, permitted concluding the procedure without converting to cardiopulmonary bypass. Intraoperative transesophageal echocardiography demonstrated normal biventricular function without new segmental acinesia. In the hypothesis of vasoplegia both patients received methylene blue $(1.5 \mathrm{mg} / \mathrm{kg}$ intravenously) in 20 minutes with a rapid improvement of mean arterial pressure $(80 \mathrm{~mm} \mathrm{Hg})$.

At the end of the operation, the patients were transferred to the intensive care unit and had an uneventful postoperative course.

\section{Discussion}

Lithium $\left(\mathrm{Li}^{+}\right)$, the primary drug used for the treatment of bipolar (maniac-depressive) disorders, may induce prolonged sleep time after barbiturate anesthesia, enhanced neuromuscular blockade after muscle relaxant administration, and cardiac conduction abnormalities. ${ }^{1}$ The mechanism of action of $\mathrm{Li}^{+}$as a mood-stabilizing agent remains unknown. Therapeutic doses of lithium interfere with the metabolism of cathecolamines that are involved in the pathophysiology of the troubles of humor; $\mathrm{Li}^{+}$also inhibits the liberation of norepinephrine and dopamine from the nervous terminations, strengthens the liberation of serotonin, and increases the presynaptic reuptake and storage of catecholamines. Furthermore, it has interactions with drugs like angiotensin-converting enzyme inhibitors (which reduce $\mathrm{Li}^{+}$clearance with possible $\mathrm{Li}^{+}$ toxicity) and beta-blockers (which enhance the central depression induced by lithium).

In light of these pharmacodynamic properties, in these patients we suspected that chronic lithium therapy played a role in the unresponsiveness to vasoconstrictor agents. Lithium should be discontinued before surgery, at least the day of the operation, especially when high blood pressures are requested during surgery. $^{2}$

Methylene blue inhibits the enzyme guanylate cyclase, avoiding the cyclic guanosine 3'5'-monophosphate-dependent vasore- 
laxant effects of nitric oxide in the smooth muscle of vessels. It has been used as an unconventional drug to treat refractory vasoplegia after cardiopulmonary bypass, anaphylaxis, and septic shock. ${ }^{3-5}$

We especially appreciated its use in these patients because the alternative drug (norepineprine), in the postoperative period of cardiac surgery, could be detrimental, especially after CABG. No data exist on the effects of methylene blue on arterial conduits.

\section{Conclusion}

We recommend lithium to be discontinued before surgery and suggest methylene blue as an alternative drug to treat vasodilatory shock in the perioperative period of cardiac surgery.

We are in debt to Gherbi Giordano, RN, for the care provided to these patients.

\section{References}

1. Goodman LS, Limbird LE, Milinoff PB, Ruddon RW, Gilman AG, Hardman JG, editors. Goodman and Gilman's pharmacological basis of therapeutics. 8th ed. New York: Pergamon Press; 1990.

2. Berkowitz DE, Richardson C, Elliott DA, et al. Hypotension resistant to therapy with $\alpha$ receptor agonists complicating cardiopulmonary bypass: lithium as a potential cause. Anesth Analg. 1996;82:1082-5.

3. Grayling M, Deakin CD. Methylene blue during cardiopulmonary bypass to treat refractory hypotension in septic endocarditis. $J$ Thorac Cardiovasc Surg. 2003;125:426-7.

4. Pagni S, Austin EH. Use of intravenous methylene blue for the treatment of refractory hypotension after cardiopulmonary bypass. J Thorac Cardiovasc Surg. 2000;119:1297-8.

5. Evora PR. Should methylene blue be the drug of choice to treat vasoplegias caused by cardiopulmonary bypass and anaphylactic shock? J Thorac Cardiovasc Surg. 2000;119:632-4.

\section{Pathologic findings of aortic redissection after glue repair of proximal aorta}

Masao Yoshitatsu, MD, ${ }^{a}$ Fumikazu Nomura, MD, ${ }^{a}$ Akira Katayama, MD, ${ }^{a}$ Kentaro Tamura, MD, ${ }^{a}$ Keijiro Katayama, MD, ${ }^{a}$ Katsuhiko Ihara, $\mathrm{MD},{ }^{\mathrm{a}}$ and Yutaka Nakashima, MD, PhD, ${ }^{\mathrm{b}}$ Hiroshima and Fukuoka, Japan

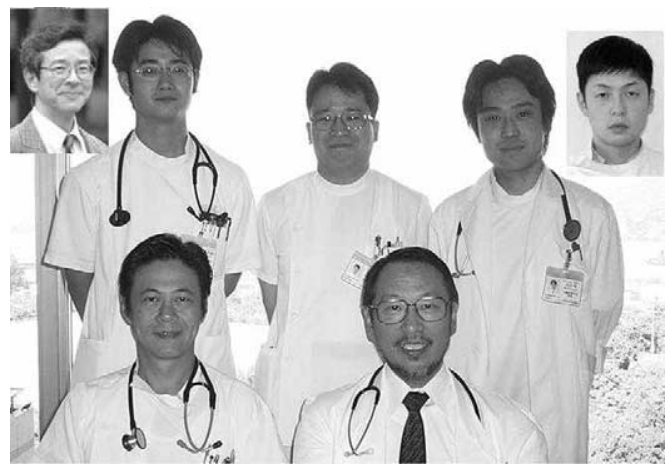

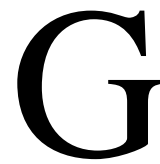
elatin-resorcinol-formaldehyde (GRF) glue (Cardial, Technopole, Sainte-Etienne, France) has become the standard choice in the repair of type A dissections. ${ }^{1}$ Several authors have reported the incidence of redissection of the aortic wall just proximal to the anastomosis. The causes remain controversial and some investigators reported that redissection might be caused by necrosis of the aortic wall caused by GRF glue. ${ }^{2-4}$ We present our clinical experience with redissection of the aortic root late after repair of type A aortic dissection.

\footnotetext{
From the Division of Cardiovascular Surgery, National Kure Medica Center, ${ }^{\mathrm{a}}$ Hiroshima, Japan, and Department of Pathophysiological and Experimental Pathology, Graduate School of Medical Sciences, Kyushu University, ${ }^{\mathrm{b}}$ Fukuoka, Japan.

Received for publication Aug 18, 2003; accepted for publication Sept 15, 2003.

Address for reprints: Masao Yoshitatsu, Division of Cardiovascular Surgery, National Kure Medical Center, 3-1, Aoyama, Kure, Hiroshima 7370023, Japan (E-mail: yoshitatsu@kure-nh.go.jp).

J Thorac Cardiovasc Surg 2004;127:593-5

$0022-5223 / \$ 30.00$

Copyright $\odot 2004$ by The American Association for Thoracic Surgery

doi:10.1016/j.jtcvs.2003.09.021
}

\section{Clinical Summary}

A 62-year-old male patient had total aortic arch replacement because of aortic dissection (Stanford type A) in December 1999. The distal lumen was fixed with GRF glue and the proximal aortic stump was reinforced with a 1-cm glued Xenomedica strip (Baxter Healthcare Co, Deerfield, Ill) outside and $0.5 \mathrm{~cm}$ of 2-mm polytetrafluoroethylene sheet (Gore-Tex; W. L. Gore \& Associates, Inc, Flagstaff, Ariz) inside with mattress sutures from inside to outside, and a 28-mm straight Hemashield graft (Meadox Medicals, Oakland, NJ) was anastomosed. The patient's hospital course was unremarkable, without any complications, and he was discharged from the hospital 5 weeks after the operation.

During the 3 years after operation, contrast-enhanced chest computed tomographic (CT) scans were performed once or twice a year and redissection was not detected. Heart murmur was not audible. As the CT scan on March 2002 revealed redissection of the aortic root, reoperation was considered. At this time diastolic murmur was audible and echocardiography showed moderate aortic regurgitation. Only 2 months later echocardiography demonstrated that aortic regurgitation was becoming severe.

The patient underwent aortic root replacement on July 2002. The proximal aortic wall seemed necrotic at the site where GRF glue had been used previously. The intimal layer from the left coronary to right coronary (posterior side) was disrupted from the anastomotic site, which caused the formation of a pseudo- 